\title{
Publisher Correction: Colonic diverticular disease
}

Antonio Tursi, Carmelo Scarpignato, Lisa L. Strate, Angel Lanas, Wolfgang Kruis, Adi Lahat and Silvio Danese

Published: 26 March 2020 Nature Reviews Disease Primers 6, Article number: 20 (2020) https://doi.org/10.1038/s41572-020-0153-5

Published online 26 March 2020

In the originally published version, an acknowledgement was not included. This section has now been updated to state: L.L.S. acknowledges NIH funding for her research (R01DK101495 and R01DK103915).

https://doi.org/10.1038/s41572-020-0176-y I Published online: 29 April 2020

(c) Springer Nature Limited 2020 